Original Research Article

\title{
A study of drug utilization pattern and pharmacoeconomic of antidiabetic drugs in patients attending a teaching hospital
}

\author{
Shanthi M.*
}

Department of Pharmacology, Tirunelveli Medical College, Tirunelveli, Tamil Nadu, India

Received: 13 February 2018 Accepted: 12 March 2018

\section{*Correspondence to:}

Dr. Shanthi M.,

Email: drshanthisenthilbabu @gmail.com

Copyright: (c) the author(s), publisher and licensee Medip Academy. This is an openaccess article distributed under the terms of the Creative Commons Attribution NonCommercial License, which permits unrestricted noncommercial use, distribution, and reproduction in any medium, provided the original work is properly cited.

\begin{abstract}
Background: Drug utilization research establishes the current trend in the use of antidiabetic drugs including the new drug and to identify irrational prescription. Methods: A cross-sectional study was conducted for a period of one year (between August 2013 to August 2014) at outpatient department of Medicine, Sree Mookambika Institute of Medical Sciences, Kulasekharam, Kanyakumari District, Tamil Nadu.

Results: A total of 169 prescriptions were evaluated during the study period. Diabetes mellitus was predominant among the female population in this region. Demographic details of the patient included in the study were mean weight $67.56 \mathrm{~kg}$, mean height $155 \mathrm{~cm}$ and average body mass index $27.82 \mathrm{~kg} / \mathrm{m}^{2}$. All the patients were diagnosed and were known case of type 2 diabetes mellitus. Systemic hypertension was the frequently encountered co-morbid conditions associated with this endocrine disorder. Metformin was the drug chosen for managing diabetes as monotherapy and $73 \%$ of the patients were on combination of antidiabetic drugs. Glimepiride with metformin was the combination therapy frequently prescribed during the study period. Pharmacoeconomic analysis identified that drugs prescribed by brand name were costlier compared to generic equivalent.

Conclusions: Utilization of antidiabetic drug therapy in this region has shown a changing trend compared to the previous studies. There is a gradual increase in the prescription of metformin and dramatic increase in the use of newer drugs like pioglitazone, voglibose and sitagliptin. Pharmaeconomic analysis revealed that glibenclamide was least expensive while sitagliptin was most expensive in this study.
\end{abstract}

Keywords: Drug utilization, Diabetes mellitus, Irrational, Monotherapy, Pharmacoeconomic, Prescription

\section{INTRODUCTION}

Diabetes mellitus (DM) is a metabolic disorder characterized by hyperglycaemia due to absolute or relative deficiency of insulin. ${ }^{1}$ Multiple organs undergo secondary pathophysiological changes due to this altered metabolism. Majority of end stage renal disease (ESRD), nontraumatic lower extremity amputations and adult blindness are complications due to DM. ${ }^{1-3}$ This non communicable disease is an emerging epidemic and India topped the world in 2007 with 31.7 million population affected with DM. ${ }^{4}$ Prevalence of DM in Tamil Nadu was found to be $10.4 \%$ in a study done by Indian Council of Medical Research. ${ }^{5}$

Management of DM require both non pharmacological and pharmacological interventions. Parenteral insulin preparation and oral hypoglycaemic medication are the currently available pharmacotherapy of DM. Drug utilization identifies the use of drugs in a society considering medical, social and economic consequences. Drug utilization study (DUS) can predict the rational use of drug in a population. Drug prescribed is considered 
rational if the patients receive medication appropriate to their clinical needs in doses that meet their own individual requirements for an adequate period of time and at the lowest cost to them and their community. ${ }^{6}$

DM requires lifelong therapy and one of the important factor deciding compliance of patient is the cost of therapy. Rationality of antidiabetic therapy can be justified by treating the ailment with appropriate drug that can ensure immense therapeutic benefit in patients with minimum cost of therapy. ${ }^{7}$ Till date no study on drug utilization pattern and pharmacoeconomic profile of antidiabetic drugs is conducted in this institution. Hence it has been proposed to conduct the study in the Medicine out-patient department of this institution.

The objective of the study is to assess the drug utilization pattern and pharmacoenomic analysis of antidiabetic drugs.

\section{METHODS}

The cross-sectional study was done in outpatient department (OPD) of Medicine, Sree Mookambika Institute of Medical Sciences, Kulasekharam, Kanyakumari district, Tamil Nadu from August 2013 to August 2014.

The study was conducted after getting approval from Instituitional Human Ethics Committee (IHEC). All the diabetic patients attending the Medicine OPD were included in the study. Patients attending the Medicine OPD for re-fill of antidiabetic drugs who have been given recruitment number were excluded from the study. Informed written consent was obtained from each study subject. Details of each study subject were recorded in a predesigned case record form. Prescribed antidiabetic drugs details including formulation, dose, frequency, duration, route of administration and whether taken before or after food was noted in the case record form. Cost of antidiabetic therapy for a period of one month was calculated. Data collected were presented as percentages in tables and figures.

\section{RESULTS}

The demographic profile of 169 diabetic patients is given in Table 1. In the current study the age group commonly affected was found to be between 61 to 70 years. Gender wise distribution of diabetic patients shows predominance among the female patients accounting 111 prescriptions and remaining being male. The mean weight of diabetic patients accounted during the study was $67.56 \mathrm{~kg}$. Average height of the diabetic patients in this study was $155 \mathrm{~cm}$. Body mass index was calculated as mean and was found to be $27.82 \mathrm{~kg} / \mathrm{m}^{2}$.

The pie diagram represented in Figure 1 give details of antidiabetic drugs as prescribed by the physician. Out of 192 drugs prescribed, more percentage of drugs was prescribed by brand name and drugs prescribed by trade name were only $13 \%$.

Table 1: Demographic profile of the diabetic patients on antidiabetic therapy.

\begin{tabular}{|c|c|c|c|}
\hline \multicolumn{2}{|c|}{$\begin{array}{l}\text { Demographic } \\
\text { characters }\end{array}$} & Number & $\begin{array}{l}\text { Percentage } \\
(\%)\end{array}$ \\
\hline \multirow{6}{*}{$\begin{array}{l}\text { Age } \\
\text { (years) }\end{array}$} & 31 to 40 & 8 & 5 \\
\hline & 41 to 50 & 34 & 20 \\
\hline & 51 to 60 & 54 & 32 \\
\hline & 61 to 70 & 58 & 34 \\
\hline & 71 to 80 & 11 & 7 \\
\hline & 81 to 90 & 4 & 2 \\
\hline \multirow[t]{2}{*}{ Sex } & Male & 58 & 34.31 \\
\hline & Female & 111 & 65.6 \\
\hline \multicolumn{2}{|c|}{ Weight (kg) } & \multicolumn{2}{|c|}{$67.56 \pm 14.17 *$} \\
\hline \multicolumn{2}{|c|}{ Height (cm) } & \multicolumn{2}{|c|}{$155 \pm 0.04 *$} \\
\hline \multicolumn{2}{|c|}{ BMI $\left(\mathrm{kg} / \mathrm{m}^{2}\right)$} & \multicolumn{2}{|c|}{$27.82 \pm 5.05^{*}$} \\
\hline
\end{tabular}

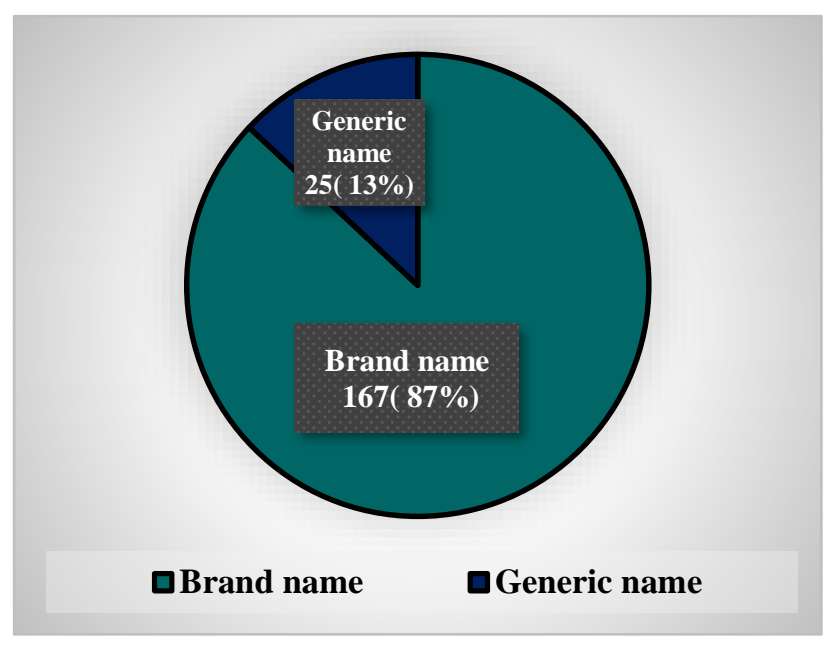

Figure 1: Number of antidiabetic drugs prescribed by generic name and brand name.

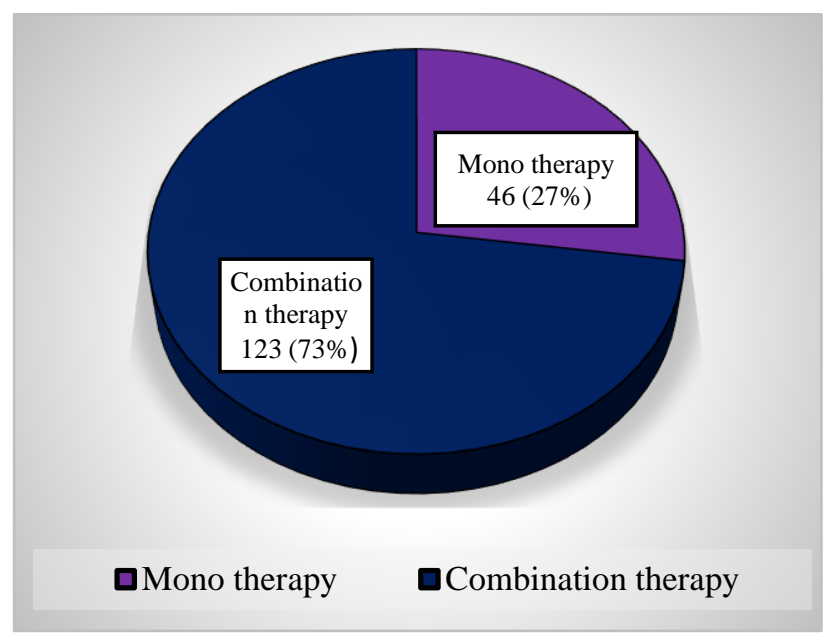

Figure 2: Percentage of prescription of antidiabetic drugs as monotherapy and combination therapy. 
Figure 2 depicts the prescribing of antidiabetic drugs as a single therapy or combination therapy. Managing DM with more than two drugs was advocated for $73 \%$ of the patients and the remaining being with one drug.

Various number of drugs prescribed in combination therapy is shown in Figure 3. Majority of patients were prescribed with 2 drug combination therapy and the remaining with 3 and 4 drug combination therapies.

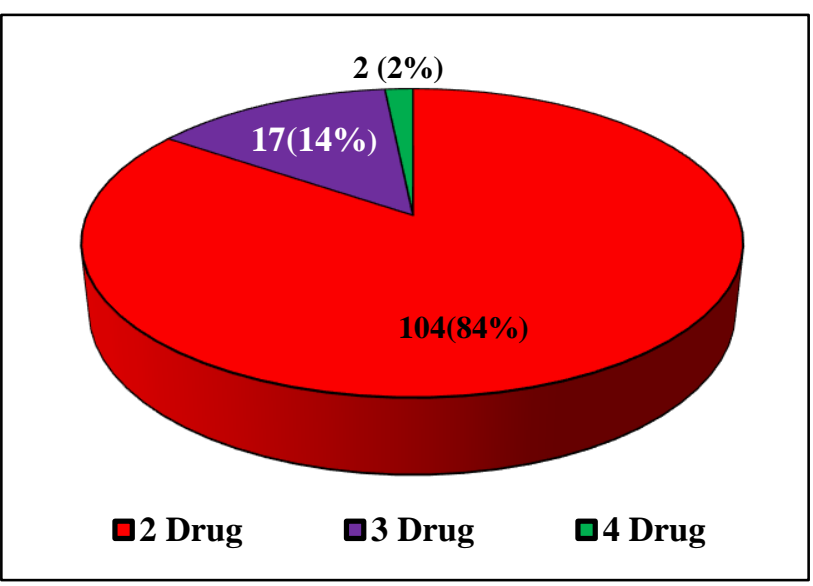

Figure 3: The percentage wise distribution of antidiabetic drugs as combination therapy.

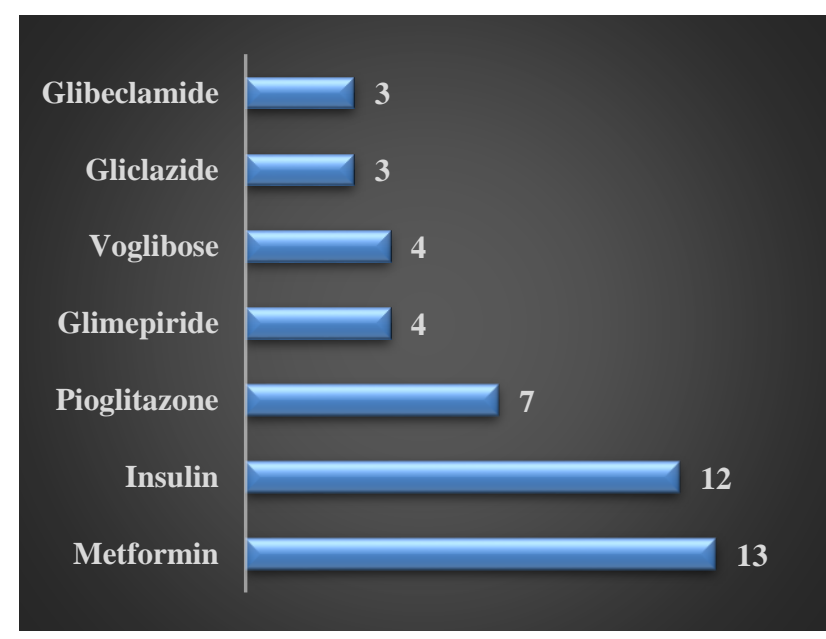

Figure 4: The number of prescriptions of antidiabetic drugs as monotherapy.

Bar diagram in Figure 4 depicts the drugs used as monotherapy. Frequently utilized drug as monotherapy was metformin, prescribed in 13 patients. DM treated in 12 with insulin, 7 with pioglitazone, 4 with glimepiride, 4 with voglibose, 3 with gliclazide and the rest with glibenclamide.

Figure 5 representing the drugs used in 2 drug combination therapy. 80 prescriptions contained a combination of glimepiride and metformin which is the highest among the 2-drug combination therapy. Metformin was prescribed with glipizide in 14 , glibenclamide in 2 , pioglitazone in 2 , voglibose in 2 and insulin in 2. Pioglitazone was prescribed in 2 patients either with glimepiride or glipizide.

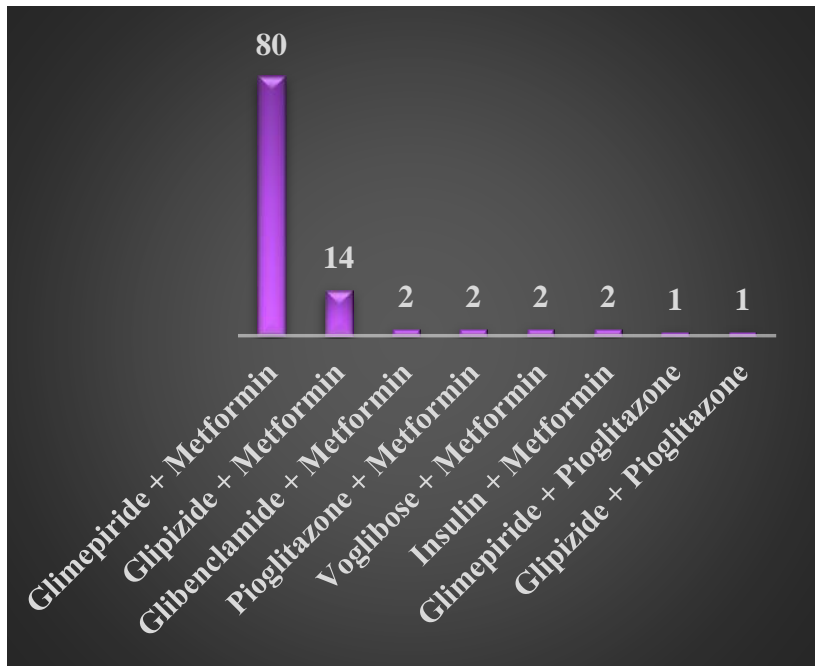

Figure 5: The number of prescriptions of antidiabetic drugs as combination of 2 drugs.

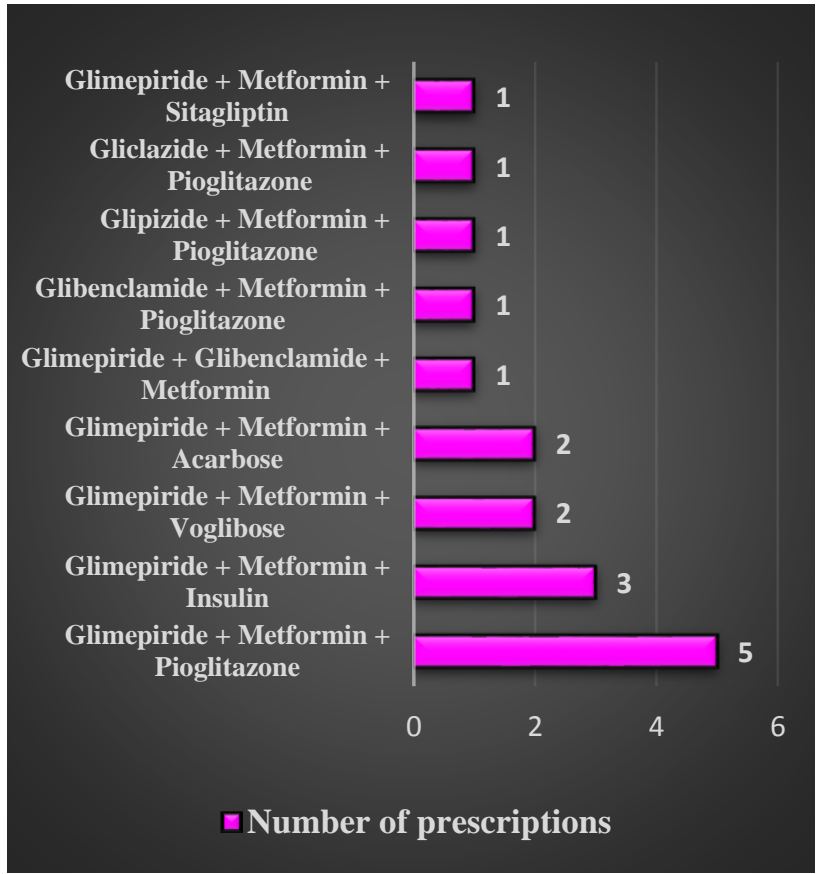

Figure 6: The number of prescriptions of antidiabetic drugs as combination of 3 drugs.

Glimepiride, metformin and pioglitazone was most commonly accounted in 5 prescriptions among the 3 drug combination therapy. Glimepiride and metformin was prescribed with insulin in 3 , voglibose in 2, acarbose in 2 and glibenclamide in 1. Pioglitazone and metformin was given in combination with sulphonylurea group (glibenclamide, glipizide or gliclazide) in 3 patients. One prescription contained a combination of glimepiride, metformin and sitagliptin as viewed in Figure 6. 
Cost of therapy per month in Indian rupee (INR) for oral antidiabetic drugs prescribed in generic and brand name are individually represented as bar diagram in Figure 7.
Pharmacoeconomic evaluation shows that cost of therapy was higher with branded drugs while comparing with the generic equivalent.

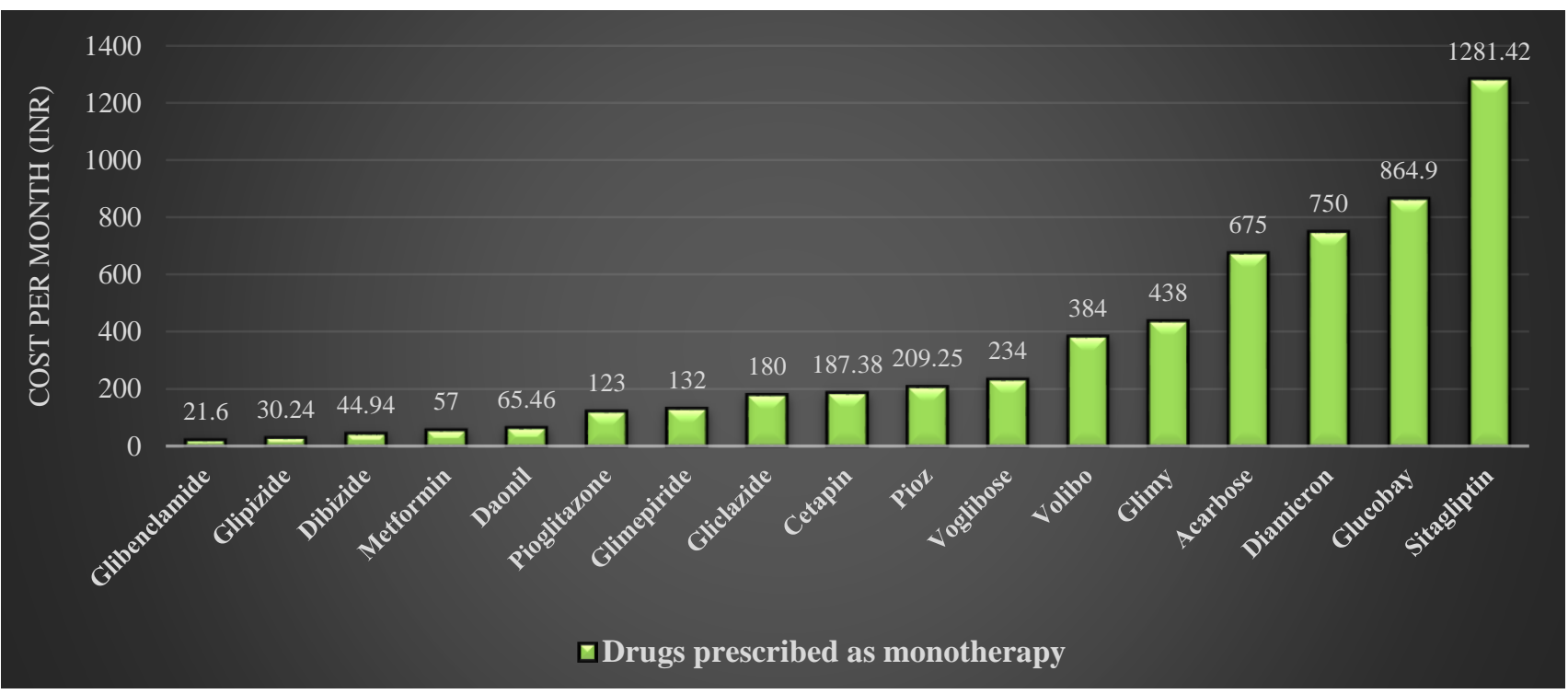

Figure 7: Cost of therapy (INR) per month for drugs prescribed as monotherapy.

Fixed dose combination with 3 drugs was more expensive compared to combination with 2 drugs. Cost per month in INR for combination therapy used in this study is given in Figure 8.

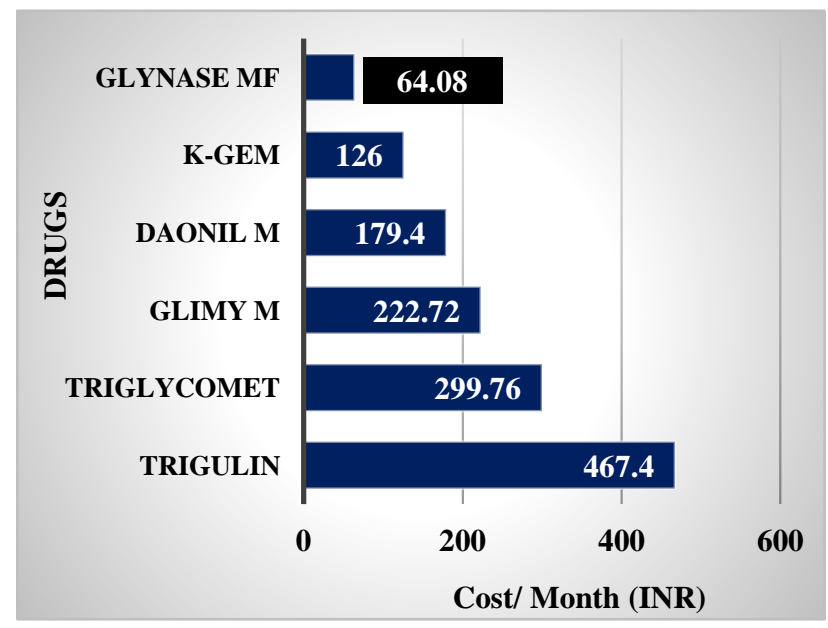

Figure 8: Cost of therapy (INR) per month for drugs prescribed as combination therapy.

Cost per unit of insulin preparation utilized in this study is represented as bar diagram in Figure 9.

\section{DISCUSSION}

The present study was done to establish the current trend in the prescription pattern of antidiabetic drugs in the outpatient department of Medicine, Sree Mookambika
Institute of Medical Sciences, Kulasekharam, Kanyakumari district. This study has shown the prescription pattern of antidiabetic drugs including rationality in this part of South India. Drug utilization study can improve the quality of treatment by managing this non communicable disease with a cost effective drug prescribed in generic name.

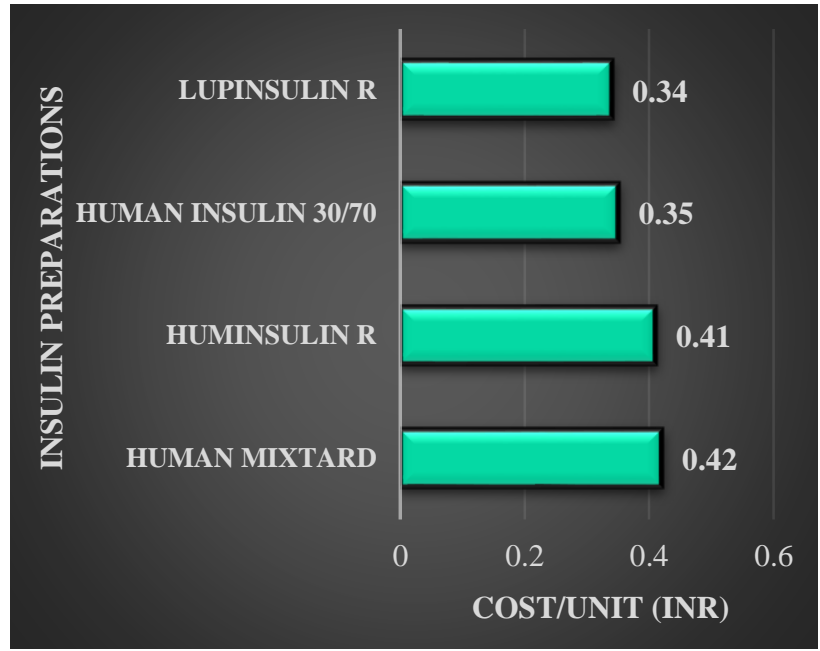

Figure 9: Cost of therapy (INR) per unit of various insulin preparations prescribed.

This study gave information regarding the frequency of prescription of antidiabetic medication which was higher in women than in men. This is found to be similar to the results obtained from previous study. ${ }^{8}$ 
Obesity and lack of physical activity plays an important role in the development of DM which can further complicate the condition and diminishes the response to treatment. Body mass index in men and women were 28.01 $\mathrm{kg} / \mathrm{m}^{2}$ and $27.82 \mathrm{~kg} / \mathrm{m}^{2}$ respectively. Average BMI of male and female were 37 and 26 respectively in a study conducted in Chennai. ${ }^{9}$

In this study there was a marked decrease in the prescription of drugs by generic name. Drugs prescribed by brand name and generic name were $167(87 \%)$ and 25 (13\%) respectively. This observation was similar to a study done in elderly patients. ${ }^{10}$

In our study $73 \%$ of the prescriptions were as combination therapy and $27 \%$ as monotherapy. There was a decrease in the use of combination therapy compared to the previous study. ${ }^{9}$ Metformin was the most frequently prescribed monotherapy in our study. In previous study done in Uttar Pradesh. ${ }^{11}$ sulphonylurea was the most commonly prescribed class of drug as monotherapy. Switching over to biguanides is a changing trend in the utilization of antidiabetic medication. In our study following biguanides, insulin was used as a single drug to control hyperglycaemia. Study done in South India showed a predominant use of parenteral insulin instead of oral hypoglycaemics. ${ }^{12}$ In the present study there is a marked increase in the use of thiazolidinediones compared to earlier study. ${ }^{9}$ Alpha-glucosidase inhibitors were also used in few prescription. Utilization of sulphonylurea as monotherapy has decreased while comparing with a prospective study. ${ }^{10}$

In this cross-sectional study biguanides was one of the drug utilized in combination therapy. Sulphonylureas were more frequently prescribed along with metformin. Among the sulphonylureas, glimepiride was most commonly used followed by glipizide. Glibenclamide was the most commonly prescribed sulphonylureas in the year 2003. ${ }^{13}$ This gradual change over may be due to decrease in the incidence of hypoglycaemic episodes. In our study pioglitazone and voglibose were the newer drugs included in fewer prescriptions. Voglibose has a very good control over postprandial hypoglycaemia which is an important contributor in development of microvascular complication. ${ }^{3}$

In this current study, prescriptions containing 3 drug combination therapies were advocated in $10.05 \%$ of cases. Alpha-glucosidase inhibitors voglibose, acarbose and DPP-4 inhibitors sitagliptin were the newer drugs prescribed in few patients during the analysis of prescription pattern in our study.

Prescription pattern contribute to the adherence to medication. This is more important in DM since it requires lifelong management. Adherence to the prescribed drug depends on cost effective drug with least adverse effect. ${ }^{10}$ The least expensive preparation in our study was metformin and sitagliptin being the most expensive.
Limitations of our study were socioeconomic state of the diabetic patients was not analysed and glycaemic control was not assessed. The availability of drugs in the hospital and the intake by the patients in the various age groups would have been a better method of DUS.

\section{CONCLUSION}

In cross sectional study conducted during the period of august 2013 to august 2014 to evaluate the drug utilization pattern of antidiabetic drugs found that the $73 \%$ of drug prescriptions were by monotherapy and $23 \%$ by combination therapy and all were found to be rational. The study also showed that the $86.98 \%$ of prescriptions were by brand names and rest were by generic names, The pharmacoeconomics of the antidiabetic drugs prescribed in the study revealed that glibenclamide was the least expensive and sitagliptin as the most expensive drugs prescribed as monotherapy and in the combination therapy the least expensive was glipizide with metformin and most expensive was the combinations of glimepiride, metformin and pioglitazone.

\section{ACKNOWLEDGEMENTS}

Authors would like to thank the Department of Medicine for their cooperation to conduct the study.

Funding: No funding sources

Conflict of interest: None declared

Ethical approval: The study was approved by the Institutional Ethics Committee

\section{REFERENCES}

1. Powers AC. Diabetes mellitus. In: Lango LD, Fauci AS, Kasper DL, Hauser SL, editors. Harrison's Principle of Internal Medicine. Vol II. $18^{\text {th }}$ Ed. New Delhi: McGraw Hill;2012:2968-3003.

2. Rang HP, Dale MM, Ritter JM, Flower RJ, Henderson $\mathrm{G}$. The control of blood glucose and drug treatment of diabetes mellitus. $7^{\text {th }}$ Ed. London: Elsevier. 2007:37284.

3. Powers CA, D’Alessio D. Endocrine pancreas and pharmacotherapy of diabetes mellitus and hypoglycemia. In. Laurence LB, John SL, Keith LP editors. Goodman and Gilman's Pharmacological Basis of Therapeutics $12^{\text {th }}$ Ed. New Delhi:McGrawHill;2011:1238-73.

4. Kaveeshwari SA, Cornwall J. The current state of diabetes mellitus in India. Australas Med J. 2014;7(1):45-8.

5. Anjana RM, Pradeepa R, Deepa M, Datta M, Sudha V, Unnikrishnan R, et al. Prevalence of diabetes and prediabetes (impaired fasting glucose and/or impaired glucose tolerance) in urban and rural India: phase 1 result of the Indian council of medical research-India Diabetes (ICMR-INDIAB) study. Diabetol. 2011;54:3022-7. 
6. Shalini S, Ravichandran V, Mohanty BK, Dhanaraj SK, Saraswathi R. Drug utilization studies-An overview. Inter $\mathbf{J}$ Pharmaceut Sci Nanotechnol. 2010;31:803-10.

7. Mandavi, Cruz SD, Sachdev A, Tiwari P. Adverse drug reactions and their risk factors among Indian ambulatory elderly patients. Indian $\mathbf{J}$ Med Res. 2012;136:404-10.

8. Kumar MA, Nizar A, Shailaja K, Ramasamy C. A study on prescribing pattern and potential drug-drug interactions in type 2 diabetes mellitus (inpatients) in a tertiary care teaching hospital. Der Pharmacia Letter. 2011;3(4):13-9.

9. Akila L, Sandozi T, Devi AKG, Kumar JS, Balasubramanian A, Rani RJ. Drug utilization study of oral anti-diabetic drug at a tertiary care (SRM Medical College) hospital in Chennai. Int $\mathbf{J}$ Med Res. 2011;1(3):177-82.

10. Acharya KG, Shah KN, Solanki ND, Rana DA. Evaluation of antidiabetic prescription, cost and adherence to treatment guidelines: A prospective, cross-sectional study at a tertiary care teaching hospital. J Basic Clinical Pharm. 2013;4(4):82-7.

11. Shahir AQ, Kauser S, Dharmender G, Ahmad AN. Prescribing patterns of antidiabetic medications in a tertiary care teaching hospital, Bareilly, UP, India. J Pharm Scientific Innovation. 2013;2(1):41-6.

12. Abdi SAH, Churi S, Kumar YSR. Study of drug utilization pattern of antihyperglycemic agents in a South Indian tertiary care teaching hospital. Indian J Pharmacol. 2012;44(2):210-4.

13. Sutharson L, Hariharan RS, Vamsadhara C. Drug Utilization study in Diabetology Outpatient setting of a tertiary hospital. Indian J Pharmacol. 2003;35:23740 .

Cite this article as: Shanthi M. A study of drug utilization pattern and pharmacoeconomic of antidiabetic drugs in patients attending a teaching hospital. Int J Basic Clin Pharmacol 2018;7:796-801. 